\title{
Novel Wide Range Speed Control of Permanent Magnet Brushless Motor Drives
}

\author{
C. C. Chan, Fellow, IEEE, J. Z. Jiang, W. Xia, and K. T. Chau, Member, IEEE
}

\begin{abstract}
This paper presents a novel approach for wide range speed control of permanent magnet (PM) brushless motor drive, including both sinewave and squarewave versions. As compared with conventional flux-weakening control, the approach takes definite advantages that it can be applied to the squarewave PM brushless motor drive directly, and even to the motor drive with negligible mutual inductances between phase windings. Moreover, it is easier to implement than flux-weakening control because no coordinate transformation is needed. The key of this approach is to make use of the transformer EMF in such a way that it weakens the rotational EMF when the motor operates above the base speed, leading to achieve constant-power operation. Computer simulation and experimental results show that the proposed approach works well.
\end{abstract}

\section{NOMENCLATURE}

E Amplitude of rotational EMF.

$e_{j} \quad$ Rotational EMF of phase $j$.

$i_{j} \quad$ Current phase $j$.

$J \quad$ Moment of inertia.

$C_{e j} \quad$ Rotational EMF coefficient of phase $j$.

$C_{T j} \quad$ Torque coefficient of phase $j$.

$L \quad$ Self-inductance of phase winding.

$L \frac{d i_{j}}{d t}$ Transformer EMF of phase $j$.

$R \quad$ Resistance of phase winding.

$T_{e} \quad$ Electromagnetic torque.

$T_{l} \quad$ Load torque.

$v_{j} \quad$ Applied voltage of phase $j$.

$V \quad$ Amplitude of applied voltage.

$\beta \quad$ Lagging angle of phase current.

$\theta \quad$ Position angle.

$\theta_{0} \quad$ Advanced conduction angle.

$\omega \quad$ Motor speed.

$\omega_{b} \quad$ Base speed.

\section{INTRODUCTION}

$\mathbf{W}$ ITH the advent of high-energy permanent-magnet (PM) materials, PM brushless motor drives are becoming more and more attractive for industrial applications and electric vehicles [1]-[3]. As compared with induction motor drives, they possess some distinct advantages such as higher power density, higher efficiency, and better controllability.

PM brushless motor drives have sinewave and squarewave versions. The sinewave PM brushless motor drive, also called

Manuscript received October 1, 1994; revised April 20, 1995.

The authors are with the Department of Electrical and Electronic Engineering, The University of Hong Kong, Hong Kong.

IEEE Log Number 9413545.

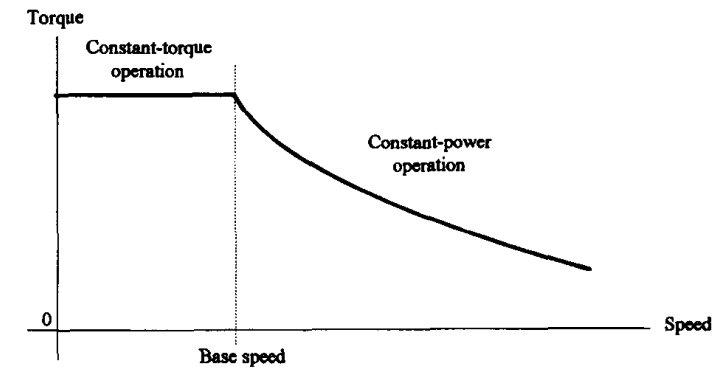

Fig. 1. Torque-speed envelope.

the PM synchronous motor drive, is fed by sinewave current and uses continuous rotor position feedback signals to control the commutation. On the other hand, the squarewave PM brushless motor drive, also called the PM brushless dc motor drive, is fed by squarewave current and uses discrete rotor position feedback signals to control the commutation. Since the interaction between squarewave current and squarewave magnetic field in the motor can produce a larger torque product than that produced by sinewave current and sinewave magnetic field, the PM brushless dc motor drive possesses higher power density than the PM synchronous motor drive [4], [5].

In most applications, particularly for electric vehicles, wide range speed control of motor drives is necessary. As shown in Fig. 1, when the motor speed is lower than the base speed, the motor drive is required to provide a constant output torque, also called constant-torque operation. On the other hand, when the speed is higher than the base speed, the load torque decreases with the speed. Thus, instead of providing a constant output torque, constant-power operation is preferred because it can significantly reduce the cost and size of the motor drive.

In general, constant-torque operation can be easily achieved in any PM brushless motor drives [6]. However, when the speed is above the base speed, the rotational EMF increases rapidly so that the motor drive usually suffers from difficulty to achieve constant-power operation. Recently, flux-weakening control has been developed to deal with this problem. By employing the field component of stator current to weaken the airgap field produced by permanent magnets, this approach allows some PM brushless motor drives to achieve constant power operation [7], [8].

Although flux-weakening control has been accepted to be applicable to the PM synchronous motor drive, it can not readily be applied to the PM brushless dc motor drive. It is because the conventional $d-q$ coordinate transformation, which 


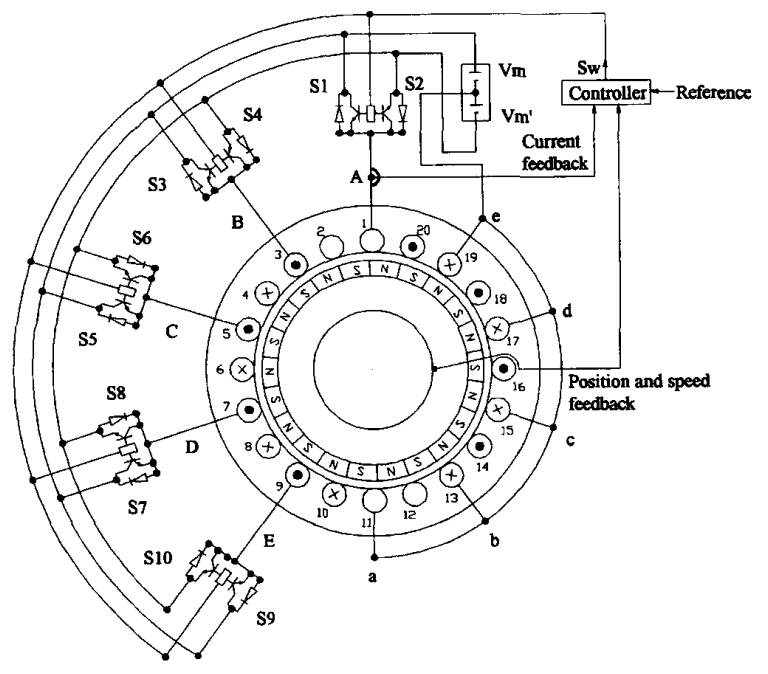

Fig. 2. Phase-decoupling PM brushless dc motor drive.

is always used in the flux-weakening control algorithm, cannot be directly applied to the squarewave motor drive. Although Fourier analysis can be employed to solve this problem by expressing the squarewave into the corresponding fundamental and harmonic sinewaves, it is too cumbersome to be realized. Moreover, when the motor is phase-decoupling such that the mutual inductance between phase windings is negligible, conventional flux-weakening control becomes ill-suited [9], [10].

It is the purpose of this paper to present a novel wide range speed control approach which allows all PM brushless motor drives to achieve constant-power operation when the motor speed is above the base speed. Moreover, since conventional flux-weakening control cannot readily be applied to the PM brushless dc motor drive and is even inapplicable to the phase-decoupling motor drive, the presentation of the proposed approach is focused on a phase-decoupling PM brushless dc motor drive.

In Section II, the principle of operation of the proposed approach to a phase-decoupling PM brushless dc motor drive is described. The corresponding mathematical model is derived in Section III. Section IV is then devoted to describing the control system of the motor drive. Finally, computer simulation and experimental results are given in Section V.

\section{PRINCIPLE OF OPERATION}

Recently, a new type of polyphase multipole PM brushless dc motor has been developed [9], [10]. This motor possesses distinct advantages of high power density, high efficiency, and excellent controllability. Because of the independence of flux paths inside the motor, the mutual inductance between phase windings is negligible. Thus, it is also called the phasedecoupling motor. As shown in Fig. 2, a 5-phase 22-pole phase-decoupling PM brushless dc motor drive is used for exemplification.

It should be noted that there are two types of electromotive forces (EMF) in the phase windings of a PM brushless motor. One is also called the rotational EMF, $e$, which is induced by

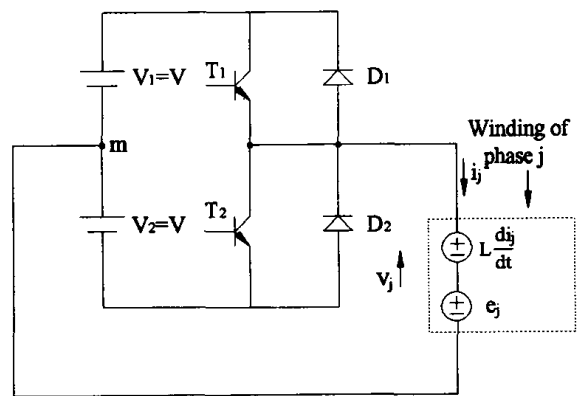

Fig. 3. Equivalent circuit diagram.

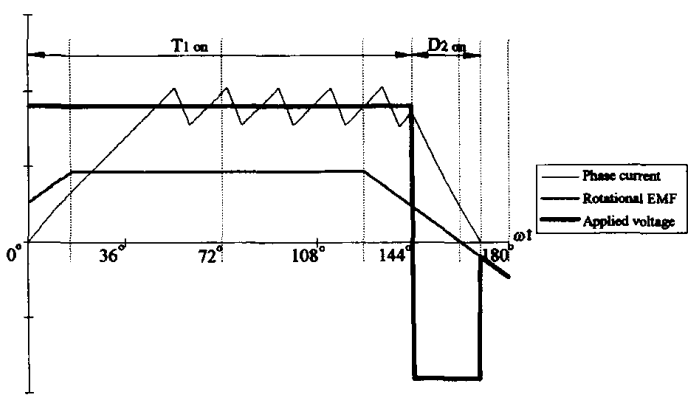

Fig. 4. Waveforms of constant-torque operation.

the magnet field of the rotating permanent magnet. Another one is also called the transformer EMF, $L \frac{d i}{d t}$, which is induced by the transformer action of the time-varying stator current in the phase windings.

The basic concept of conventional flux-weakening control is to employ the field component of stator current to weaken the airgap field produced by the permanent magnet. Thus, the rotational EMF can be effectively reduced by making use of the mutual inductance between phase windings. However, because of phase-decoupling and squarewave current shape, it is impossible to apply this approach to this motor.

Fig. 3 illustrates the per-phase equivalent circuit diagram of the motor drive. During constant-torque operation, typical circuit waveforms are shown in Fig. 4. It can be found that the rotational EMF is generally lower than the applied voltage, and is in phase with the conduction period of $T_{1}$. When the motor speed is above the base speed, the rotational EMF becomes close to the applied voltage, resulting dramatic reduction in phase current and electromagnetic torque. In order to weaken the rotational EMF in the absence of mutual inductances, the transformer EMF is purposely employed to oppose the rotational EMF during constant-power operation. As shown in Fig. 5 , the conduction period of $T_{1}$ leads the rotational EMF by a spatial angle, also called the advanced conduction angle, when the motor speed is above the base speed.

Starting from the turn-on of $T_{1}$, the first half cycle is divided into nine intervals as illustrated in Fig. 5. The operating principle is described in accordance with these intervals. In the interval 1-2, the negative rotational EMF acts to strengthen the applied voltage so that the phase current increases rapidly. In the interval $2-3$, both the applied voltage and rotational 


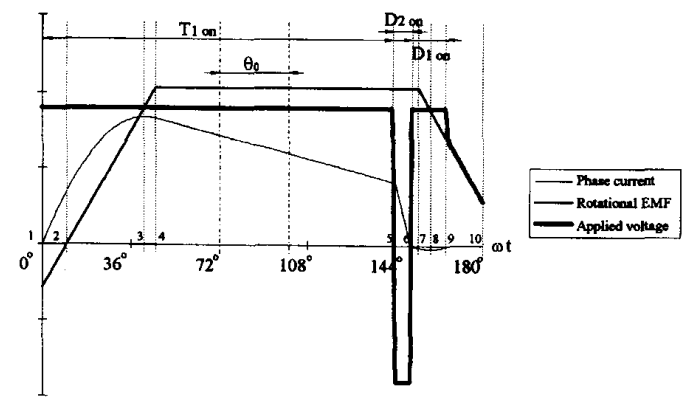

Fig. 5. Waveforms of constant-power operation.

EMF are positive. Since the applied voltage is still larger than the rotational EMF, the phase current increases gradually. Therefore, in both intervals, the transformer EMF is positive which indicates that energy is stored in the phase winding. On the other hand, in the intervals $3-4$ and $4-5$, the rotational EMF is greater than the applied voltage. Thus, the phase winding begins to release energy, and the phase current decreases gradually. Since the corresponding transformer EMF is negative, it acts to assist the applied voltage to counteract the rotational EMF. This phenomenon is the key point of this approach which is purposely employed to achieve constantpower operation. After $T_{1}$ is turned off, the phase current flows through $D_{2}$ in the interval 5-6. Since both the applied voltage and transformer EMF are negative, the phase current drops rapidly to zero. Then, in the intervals $6-7$ and $7-8$, the rotational EMF is larger than the applied voltage so that the phase current begins to flow negatively through $D_{1}$. When the rotational EMF becomes smaller than the applied voltage in the interval 8-9, the phase current goes back to zero. Since the circuit is opened in the interval 9-10, the applied voltage equals the rotational EMF. The operating principle for another half cycle is very similar and is omitted.

It should be noted that, to the best of the authors' knowledge, the use of transformer EMF to weaken the rotational EMF for obtaining constant-power operation has not been found in the literature of power electronics and drives.

\section{Mathematical Derivation}

Because of phase decoupling, the $m$-phase PM brushless dc motor can be treated as $m$ separate dc motors. Since the permanent magnet, which is mounted on the rotor surface, possesses low permeability, the induced current inside the rotor is negligible. Due to the symmetry of the motor configuration, self-inductances of phase windings are assumed to be identical. Thus, the voltage equation for the $j$ th phase of the motor can be expressed as

$$
\begin{aligned}
& v_{j}\left(\omega t+\theta_{0}-\frac{(j-1) \pi}{m}\right) \\
& =R i_{j}\left(\omega t+\theta_{0}-\frac{(j-1) \pi}{m}\right) \\
& \quad+L \frac{d i_{j}\left(\omega t+\theta_{0}-\frac{(j-1) \pi}{m}\right)}{d t}
\end{aligned}
$$

$$
+e_{j}\left(\omega t-\frac{(j-1) \pi}{m}\right) \quad j=1 \cdots m
$$

where $v_{j}$ is the applied voltage, $R i_{j}$ is the resistance drop, $L \frac{d i_{j}}{d t}$ is the transformer EMF, and $e_{j}$ is the rotational EMF. On the other hand, the electromagnetic torque and the corresponding equation of motion are given by

$$
\begin{gathered}
T_{e}(\omega t)=\sum_{j=1}^{m} e_{j}\left(\omega t-\frac{(j-1) \pi}{m}\right) i_{j}\left(\omega t+\theta_{0}-\frac{(j-1) \pi}{m}\right) \\
T_{e}(\omega t)-T_{l}-B \omega(t)=J \frac{d \omega(t)}{d t} .
\end{gathered}
$$

Equations (1) and (3) can be rewritten as

$$
\begin{aligned}
i_{j}(\omega t & \left.+\theta_{0}-\frac{(j-1) \pi}{m}\right) \\
= & \frac{1}{L} \int_{0}^{t}\left[v_{j}\left(\omega t+\theta_{0}-\frac{(j-1) \pi}{m}\right)\right. \\
& -e_{j}\left(\omega t-\frac{(j-1) \pi}{m}\right) \\
& \left.-R i_{j}\left(\omega t+\theta_{0}-\frac{(j-1) \pi}{m}\right)\right] d t+i_{j}(0) \\
\omega(t)= & \frac{1}{J} \int_{0}^{t}\left[T_{e}(\omega t)-T_{l}-B \omega(t)\right] d t+\omega(0)
\end{aligned}
$$

where $i_{j}(0)$ and $\omega(0)$ are the corresponding initial values. Since the motor possesses a unique configuration, the self inductance is obtained using the finite element method [9].

In order to obtain the analytical solution of (4), a piecewise continuous function is used to represent the phase current. For simplicity, the following assumptions are made

i) The phase winding resistance is negligible.

ii) The induced rotational EMF is trapezoidal.

iii) The initial spatial angle of phase current $j$ is zero, $\theta_{0}-$ $\frac{(j-1) \pi}{m}=0$.

iv) The initial phase current is zero, $i_{j}(0)=0$.

Starting from the moment that $T_{1}$ is turned on, the phase current can be divided into six stages over the first half cycle as shown in Fig. 5.

\section{A. Stage $I,\left[\theta_{0}+\frac{\pi}{2 m} \geq \omega t \geq 0\right]$}

This stage covers the intervals $1-2,2-3$, and $3-4$. The applied voltage is kept constant while the rotational EMF rises up linearly, which are given by

$$
\left.\begin{array}{l}
v_{j}=V \\
e_{j}=\frac{m E \omega}{\pi}\left(t-\frac{\theta_{0}}{\omega}+\frac{\pi}{2 m \omega}\right)
\end{array}\right\} .
$$

Substituting (6) into (4) and using the zero initial condition, $i_{j}(0)=i_{j, 1}=0$, the phase current can be obtained as

$$
i_{j}(\omega t)=\frac{2 V \pi-E \pi+2 m E \theta_{0}}{2 \pi \omega L} \omega t-\frac{m E}{2 \pi \omega L}(\omega t)^{2} .
$$

This stage finishes when $\omega t=\theta_{0}+\frac{\pi}{2 m}$, the corresponding phase current is expressed as

$$
i_{j, 4}=\frac{\pi+2 m \theta_{0}}{2 \pi \omega L} V+\frac{4 m^{2} \theta_{0}^{2}-4 m \pi \theta_{0}-3 \pi^{2}}{8 m \pi \omega L} E .
$$


B. Stage II, $\left[\frac{m-1}{m} \pi \geq \omega t \geq \theta_{0}+\frac{\pi}{2 m}\right]$

It covers the interval 4-5 in which both the applied voltage and rotational EMF are constant. They are given by

$$
\left.\begin{array}{l}
v_{j}=V \\
e_{j}=E
\end{array}\right\}
$$

Substituting (9) into (4) and using $i_{j}(0)=i_{j, 4}$, it yields

$$
i_{j}(\omega t)=\frac{1}{\omega L}(V-E)\left(\omega t-\theta_{0}-\frac{\pi}{2 m}\right)+i_{j, 4} .
$$

At the end of this stage, the phase current is given by

$$
i_{j, 5}=\frac{1}{\omega L}(V-E)\left(\pi-\theta_{0}-\frac{3 \pi}{2 m}\right)+i_{j, 4}
$$

It should be noted that the transformer EMF of the $j$ th phase, $L \frac{d i_{j}}{d t}$, in the intervals $3-4$ and $4-5$ can be determined using (7) and (10). Since the corresponding transformer EMF has a negative value, it assists the applied voltage to oppose the enlarged rotational EMF, leading to realize constant-power operation at high speeds.

\section{Stage III, $\left[\frac{m-1}{m} \pi+\beta \geq \omega t \geq \frac{m-1}{m} \pi\right]$}

It covers the interval $5-6$, and its duration is defined as $\beta$. At the beginning of this stage, $T_{1}$ is turned off. Thus, $D_{2}$ is forward biased and begins to conduct the phase current. The applied voltage becomes negative while the rotational EMF is unchanged. They are given by

$$
\left.\begin{array}{l}
v_{j}=-V \\
e_{j}=E
\end{array}\right\}
$$

Substituting (12) into (4) and using $i_{j}(0)=i_{j, 5}$, the phase current is expressed as

$$
i_{j}(\omega t)=-\frac{1}{\omega L}(V+E)\left(\omega t-\frac{m-1}{m} \pi\right)+i_{j, 5} .
$$

At the end of this stage, the phase current is given by

$$
i_{j, 6}=-\frac{1}{\omega L}(V+E) \beta+i_{j, 5}
$$

which is equal to zero. Hence, by using (14), the duration of this stage can be found as

$$
\beta=\frac{\omega L}{V+E} i_{j, 5}
$$

which is also called the lagging angle of phase current.

$$
\text { D. Stage } I V,\left[\frac{2 m-3}{2 m} \pi+\theta_{0} \geq \omega t \geq \frac{m-1}{m} \pi+\beta\right]
$$

This stage covers the interval 6-7. Since the rotational EMF is larger than the applied voltage, $D_{1}$ is forward biased and begins to conduct the phase current negatively. Both the applied voltage and rotational EMF are kept constant, which are given by

$$
\left.\begin{array}{l}
v_{j}=V \\
e_{j}=E
\end{array}\right\}
$$

Substituting (16) into (4) and using the zero initial condition, the phase current is expressed as

$$
i_{j}(\omega t)=\frac{1}{\omega L}(V-E)\left(\omega t-\frac{m-1}{m} \pi-\beta\right) .
$$

At the end of this stage, it is given by

$$
i_{j, 7}=\frac{1}{\omega L}(V-E)\left(\theta_{0}-\beta-\frac{\pi}{2 m}\right) .
$$

$$
\text { E. Stage } V,\left[\frac{2 m-3}{2 m} \pi+\theta_{0}+\gamma \geq \omega t \geq \frac{2 m-3}{2 m} \pi+\theta_{0}\right]
$$

It covers the intervals 7-8 and 8-9, and its duration is defined as $\gamma$. The applied voltage is kept constant while the rotational EMF decreases linearly. They are given by

$$
\left.\begin{array}{l}
v_{j}=V \\
e_{j}=-\frac{m E \omega}{\pi}\left(t-\frac{\pi}{\omega}-\frac{\theta_{0}}{\omega}+\frac{\pi}{2 m \omega}\right)
\end{array}\right\} .
$$

Substituting (19) into (4) and using $i_{j}(0)=i_{j, 7}$, it yields

$$
\begin{aligned}
i_{j}(\omega t)= & \frac{1}{\omega L}\left(V-m E+\frac{E}{2}-\frac{m \theta_{0} E}{\pi}\right) \\
& \times\left(\omega t-\frac{2 m-3}{2 m} \pi-\theta_{0}\right) \\
& +\frac{m E}{2 \pi \omega L}\left[(\omega t)^{2}-\left(\frac{2 m-3}{2 m} \pi+\theta_{0}\right)^{2}\right]+i_{j, 7} .
\end{aligned}
$$

The phase current at the end of this stage is given by

$$
i_{j, 9}=\frac{m E}{2 \pi \omega L} \gamma^{2}+\frac{V-E}{\omega L} \gamma+i_{j, 7}
$$

Since the rotational EMF falls below the applied voltage in the interval $8-9$, the phase current goes back to zero at the end of this stage. Hence, the duration of this stage can be easily obtained from (21).

\section{F. Stage $V I,\left[\pi \geq \omega t \geq \frac{2 m-3}{2 m} \pi+\theta_{0}+\gamma\right]$}

This stage covers the interval 9-10 and finishes at the end of the first half cycle. Since the circuit is opened, the applied voltage equals the rotational EMF while the phase current is always zero.

Since $i_{j}(\omega t+\pi)=-i_{j}(\omega t)$, the analytical formulae of phase current for another half cycle can readily be obtained. It should be noted that although the above derivation is based on the typical situation that $\frac{3 \pi}{2 m} \geq \theta_{0} \geq \frac{\pi}{2 m}+\beta$, the derivation for other situations can be obtained similarly.

\section{CONTROL SYSTEM}

Fig. 6 illustrates the closed-loop control system of the motor drive, which is suitable for both constant-torque and constantpower operations. Fig. 6(a) describes the system functional block diagram while Fig. 6(b) illustrates the corresponding control block diagram of phase $j$.

When the speed reference signal $\omega^{*}$ is set, the motor starts up. From the output of an encoder, the speed feedback signal $\omega$ and position feedback signal $\theta$ can be obtained. The speed error, the difference between $\omega^{*}$ and $\omega$, is then inputted into 


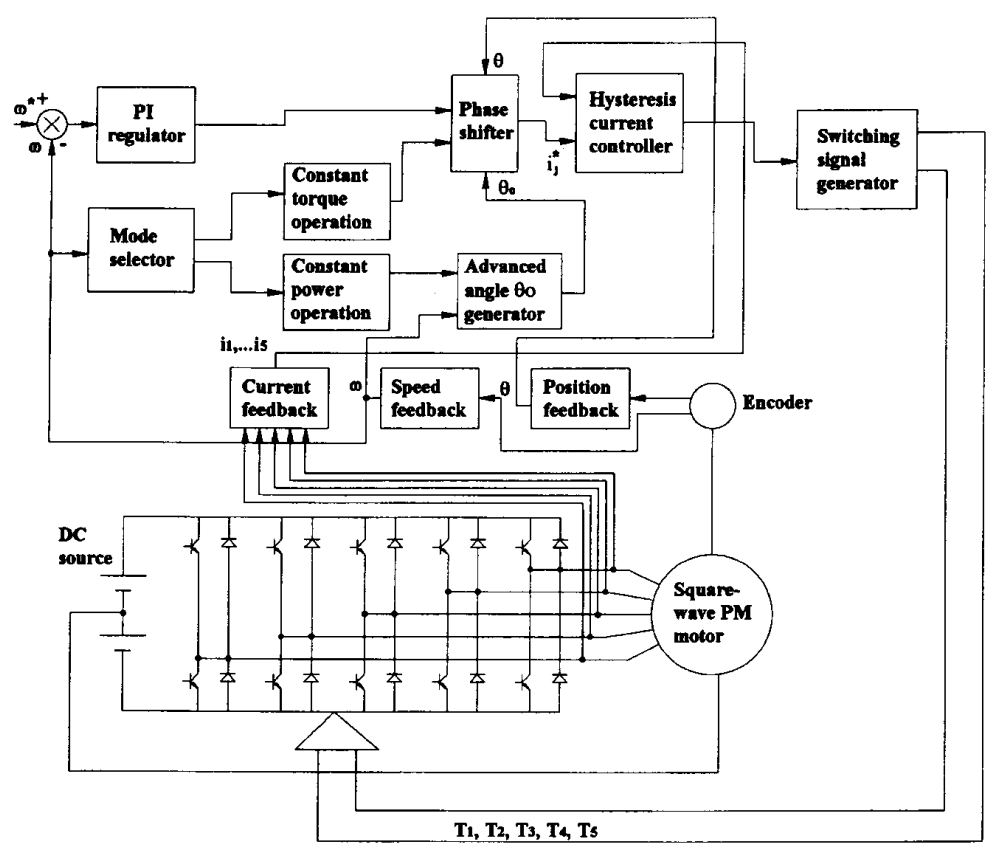

(a)

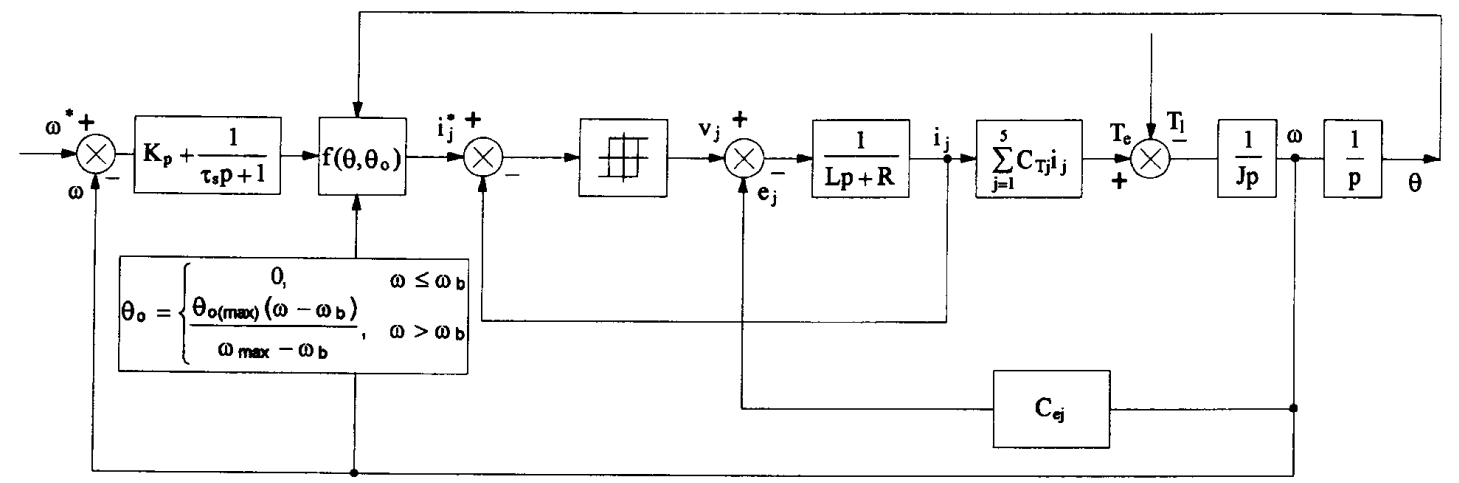

(b)

Fig. 6. Control system. (a) Functional block diagram. (b) Control block diagram.

a proportional-integral (PI) regulator where $k_{p}$ and $\tau_{p}$ are the corresponding proportional constant and time constant, respectively. This regulator is used for speed control of the motor drive. Based on the value of $\omega$, the mode selector determines which mode of operation is required. When $\omega$ is lower than or equal to the base speed $\omega_{b}$, the motor operates in the constant-torque region and the advanced conduction angle $\theta_{0}$ is set to zero. On the other hand, when $\omega$ is above $\omega_{b}$, it operates with positive $\theta_{0}$ in the constant-power region. By feeding the output signals from the PI regulator, position encoder, and advanced conduction angle generator into the phase shifter, which functions to produce the phase difference between adjacent phases, a set of current reference signals can be obtained. The difference between the current reference signal $i_{j}^{*}$ and the current feedback signal $i_{j}$ is fed into a hysteresis current controller to ensure that $i_{j}$ can track $i_{j}^{*}$ within the tolerance band. Hence, the applied voltage $v_{j}$ of the motor can be adjusted accordingly. The remaining blocks are to represent basic motor operation so that the corresponding description is omitted and symbols are defined in Nomenclature.

In order to determine the value of $\theta_{0}$ for speeds above the base speed, computer simulation of the motor is carried out. Based on the technical data of the motor quoted in Appendix, the corresponding parameters are $L=1.29 \mathrm{mH}$, $R=0.054 \Omega, J=0.0084 \mathrm{kgm}^{2}$. The simulation results are plotted as a set of motor torque-speed characteristics with different $\theta_{0}$. As shown in Fig. 7, the minimum required value of the advanced conduction angle $\theta_{0 \text { (min) }}$ increases from $0^{\circ}$ to $43^{\circ}$ so that the motor can maintain constant-power operation for the speed up to $4000 \mathrm{r} / \mathrm{min}$. For a particular $\omega, \theta_{0}$ can be further increased to a value in such a way to optimize the 


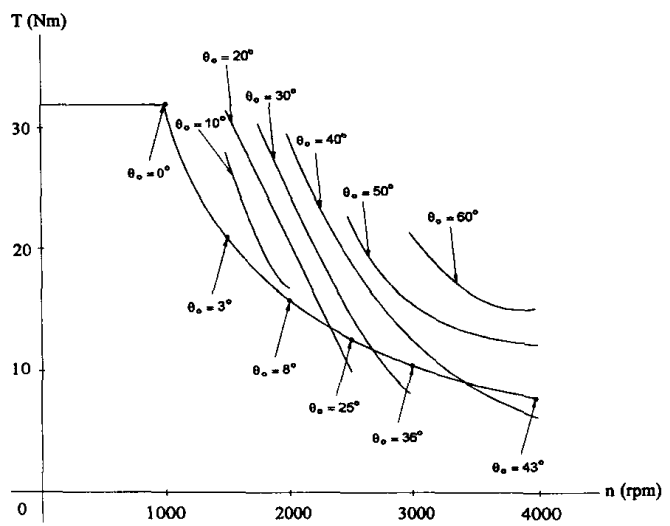

Fig. 7. Torque-speed characteristics with different advanced conduction angles.

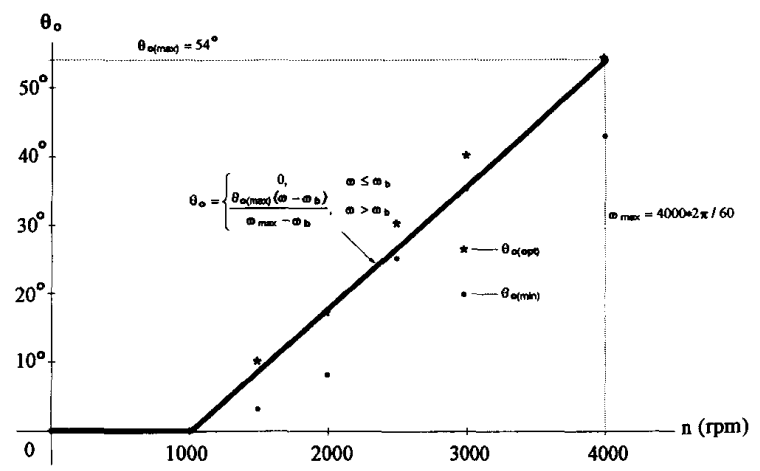

Fig. 8. Optimal advanced conduction angle model.

motor efficiency during constant-power operation. As shown in Fig. 8, the optimal advanced conduction angle $\theta_{0(\mathrm{opt})}$ is marked with " $*$ " while the corresponding $\theta_{0(\min )}$ is marked with " $\bullet$ " In order to facilitate real-time computation, a linear relationship between $\theta_{0}$ and $\omega$ is adopted for speeds above $\omega_{b}$ in constant-power operation. Notice that the resulting $\theta_{0}$ must be greater than $\theta_{0(\min )}$. Defining $\theta_{0(\max )}$ as the maximum value of the desired advanced conduction angle shown in Fig. 8, the corresponding relationship can simply be expressed as

$$
\theta_{0}= \begin{cases}0, & \omega \leq \omega_{b} \\ \frac{\theta_{0(\max )}\left(\omega-\omega_{b}\right)}{\omega_{\max }-\omega_{b}}, & \omega>\omega_{b} .\end{cases}
$$

\section{RESULTS}

In order to illustrate the transient response of the motor drive, computer simulation of the whole drive system is carried out. The PI regulator parameters are $K_{p}=80$ and $\tau_{p}=0.1 \mathrm{~s}$. When the speed command is set at $3000 \mathrm{r} / \mathrm{min}$, the corresponding advanced conduction angle is $36^{\circ}$. As shown Fig. 9, the motor takes about $0.115 \mathrm{~s}$ to reach the desired speed at no-load. Notice that the motor current is limited to $58 \mathrm{~A}$ due to overcurrent protection which will lengthen the startup time. After reaching steady state, a sudden load of 10.6

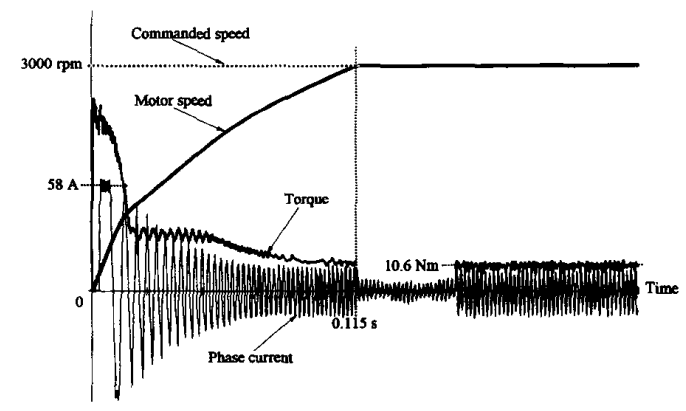

Fig. 9. Transient response.

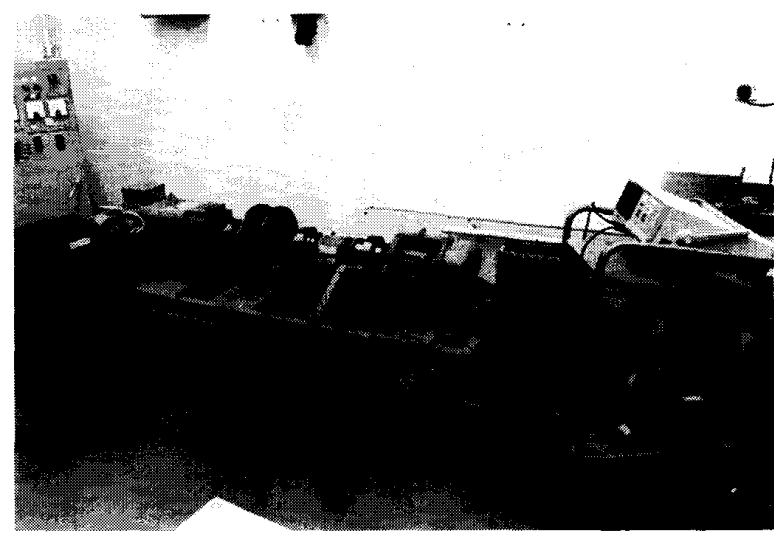

Fig. 10. Experimental set-up.

$\mathrm{Nm}$ is applied. Since there is no significant speed change, the transient response of the motor drive is good. It should be noted that the load of $10.6 \mathrm{Nm}$ is the nominal torque at 3000 $\mathrm{r} / \mathrm{min}$ during constant-power operation because it is one-third of the nominal torque at the base speed of $1000 \mathrm{r} / \mathrm{min}$.

In this paper, the concept of using the advanced conduction angle to control the transformer EMF to weaken the rotational EMF during constant-power operation is original. An experimental motor drive shown in Fig. 10 is tested to verify the proposed concept for constant-power operation. When the motor speed is 2747 , the simulated phase current waveform using the derived equations is shown in Fig. 11(a). Under the same conditions, the measured phase current waveform is shown in Fig. 11(b). It can be found that they are very similar. Furthermore, a wide range speed control test is carried out from 0 to $2747 \mathrm{r} / \mathrm{min}$ in which there is no advanced conduction angle for speeds below or equal to $1000 \mathrm{r} / \mathrm{min}$ while the angle is fixed at $28^{\circ}$ for speeds above $1000 \mathrm{r} / \mathrm{min}$. As shown in Fig. 12, the motor drive can provide both constant-torque and constant-power operations. Moreover, it can be found that the measured output torque at $2747 \mathrm{r} / \mathrm{min}$ is slightly less than the desired value for constant-power operation because the advanced conduction angle has been fixed at $28^{\circ}$. This discrepancy can be minimized by real-time adjusting the advanced conduction angle for different motor speeds. The hardware implementation of real-time control of the motor drive and the associated electric vehicle applications are now 


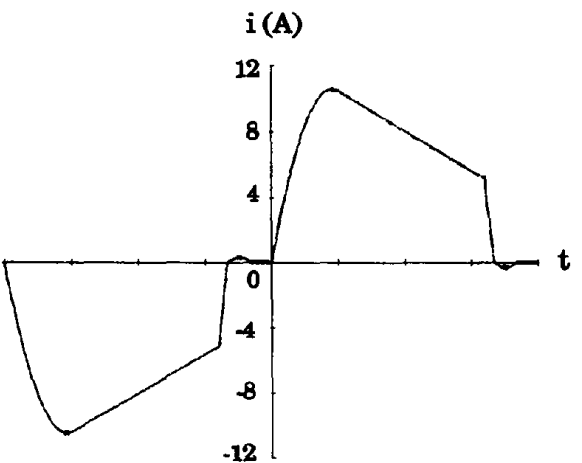

(a)

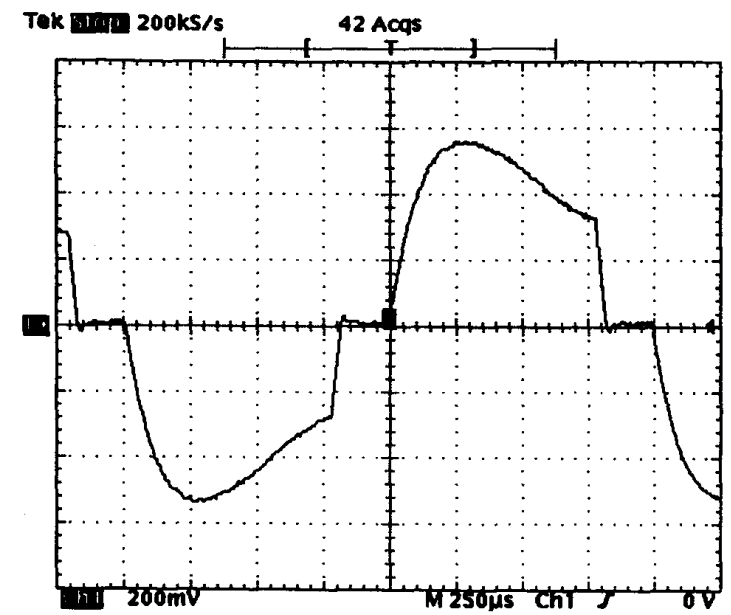

(b)

Fig. 11. Phase current. (a) Theoretical waveform (4 A/div, $250 \mu \mathrm{s} / \mathrm{div})$. (b) Experimental waveform (4 A/div, $250 \mu \mathrm{s} / \mathrm{div}$ ).

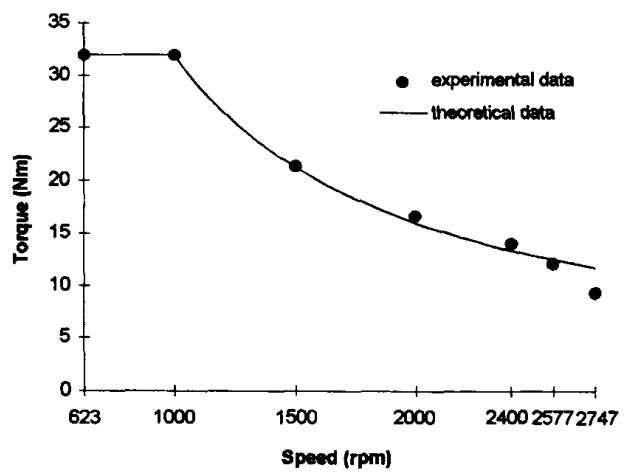

Fig. 12. Theoretical and experimental torque-speed envelopes.

being investigated, which are sufficient to form the substance for our next publication.

\section{CONCLUSION}

A novel wide range speed control approach is presented. The proposed approach is suitable for all PM brushless motor drives, including the PM synchronous motor drive and PM brushless dc motor drive. It takes definite advantages over conventional flux-weakening control-it can be directly applied to the squarewave-fed PM brushless dc motor drive; it can be uniquely applied to any brushless motor drives with negligible mutual inductances between phase windings; and it can be implemented without coordinate transformation. The originality of this approach is to employ the advanced conduction angle to control the transformer EMF in such a way that it weakens the rotational EMF when the motor operates above the base speed, leading to achieve the desired constant-power operation. A 5-phase 22-pole phase-decoupling PM brushless dc motor drive is used for exemplification, and operates up to 2.75 times the base speed. Both computer simulation and experimental verification show that the proposed approach works well.

\section{APPENDIX}

Technical Data of the Motor

$\begin{array}{ll}\text { Rated power } & 3.33 \mathrm{~kW} \\ \text { Rated voltage } & 2 \times 90 \mathrm{~V} \\ \text { Base speed } & 1000 \mathrm{rpm} \\ \text { no. of phase } & 5 \\ \text { Stator } & \\ \text { no. of slots } & 20 \\ \text { Outer diameter } & 175 \mathrm{~mm} \\ \text { Inner diameter } & 86 \mathrm{~mm} \\ \text { Length of core } & 100 \mathrm{~mm} \\ \text { Winding type } & \text { Single layer } \\ \text { no. of coils } & 10 \\ \text { Resistance per phase } & 0.054 \Omega \\ \text { Self-inductance per phase } & 1.29 \mathrm{mH} \\ \text { Slot pitch } & 1 \mathrm{slot} \\ \text { Rotor } & \\ \text { no. of poles } & 22 \\ \text { Outer diameter } & 84 \mathrm{~mm} \\ \text { Inner diameter } & 48 \mathrm{~mm} \\ \text { Magnet height } & 5 \mathrm{~mm} \\ \text { Magnet material } & \text { Nd-Fe-B }\end{array}$

\section{ACKNOWLEDGMENT}

The authors thank the TRANSACTIONS reviewers for their valuable suggestions.

\section{REFERENCES}

[1] T. I. E. Miller, Brushless Permanent-Magnet and Reluctance Motor Drives. New York: Oxford University Press, 1989.

[2] B. K. Bose, "A high-performance inverter-fed drive system of an interior permanent magnet synchronous machine," IEEE Trans. Ind. Applicat., vol. 24, pp. 987-997, 1988.

[3] C. C. Chan, "Overview of electric vehicle technology," Proc. IEEE, vol. 81, pp. $1202-1213,1993$.

[4] H. Weh, H. Mosebach, and H. May, "Design concepts and force generation in inverter-fed synchronous machines with permanent magnet excitation," IEEE Trans. Magnetics, vol. 20, pp. 1756-1761, 1984.

[5] P. J. McCleer, J. M. Bailey, J. S. Lawler and B. Banerjee, "Five phase trapezoidal back emf PM synchronous machines and drives," in Proc. European Power Electron. Conf., Florence, Italy, 1991, pp. 1-6.

[6] K. T. Chau, "Computer graphics aided design and microcomputer control of an advanced permanent magnet motor drive," M.Phil. thesis, University of Hong Kong, 1990.

[7] B. Sneyers, D. W. Novotny, and T.A. Lipo, "Field weakening in buried permanent magnet AC motor drives," IEEE Trans. Ind. Applicat., vol. 21. pp. 398-407, 1985. 
[8] T. M. Jahns, "Flux-weakening regime operation of an interior permanent-magnet synchronous motor drive," IEEE Trans. Ind. Applicat., vol. 23, pp. 681-689, 1987.

[9] C. C. Chan, J. Z. Jiang, G. H. Chen, and X. Y. Wang, "A novel high power density permanent magnet variable-speed motor," IEEE Trans. Energy Conversion, vol. 8, pp. 297-303, 1993.

[10] C. C. Chan, "A novel permanent magnet brushless de motor," UK Patent Application, 1994

[11] C. C. Chan, J. Z. Jiang, G. H. Chen, and K. T. Chau, "Computer simulation and analysis of a new polyphase multipole motor drive," IEEE Trans. Ind. Electron., vol. 40, pp. 128-143, 1993.

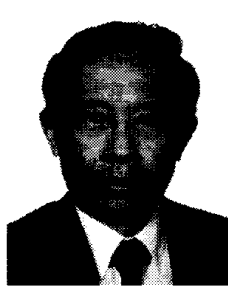

C. C. Chan (F'92) was awarded the Hon.D.Sc. degree from the University of Odessa.

He started his professional electrical engineering career in 1959 . He has been working 11 years in industry and 24 years in academic institutions. He is now the endowed Honda Professor and Head of Department of Electrical \& Electronic Engineering, the University of Hong Kong. He is also the Director of the International Research Center for Electric Vehicles. He has published 4 books and over 100 papers on electrical engineering. He was a Visiting Professor at several well known universities, including the University of California at Berkeley

Prof. Chan holds over 20 posts in international committees, and serves as Consultant to several organizations in Hong Kong and the United States. He is also a Fellow of IEE and HKIE, Chairman of an IEEE Technical Committee, and is listed in International Leaders of Achievement, Men of Achievement, Who's Who in Australasia and the Far East. $\mathrm{He}$ is the co-founder of the World Electric Vehicle Association, and is known as one of the three wise men in the international electric vehicle community.

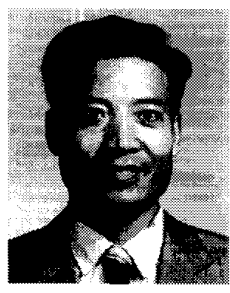

J. Z. Jiang was born in Jiangsu, China, on October 11, 1939. He received the B.E.E. and M.E.E. degrees from Shanghai Jiao-Tong University in 1962 and 1965, respectively. He obtained the Dr.-Ing. degree from the Technical University of Braunschweig, Germany, in 1988

$\mathrm{He}$ is Professor of Electrical Engineering at Shanghai University of Technology. His research interests are in high-performances variables-speed drives, electric machine design, numerical analysis of electromagnetic fields in electric machinery, the dynamic modeling of machines, and their associated power electronics. $\mathrm{He}$ has published over 20 papers, and has two patents in these fields.

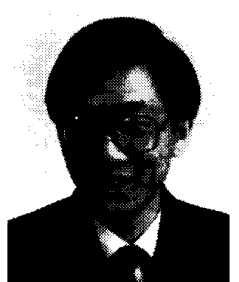

W. Xia was born in Shanghai, China, on June 16, 1965. He received the B.Sc.(Eng.) and the M.Sc.(Eng.) degrees, both in electrical engineering, from Shanghai University of Technology in 1988 and 1991, respectively. He is currently a Ph.D. candidate in the Department of Electrical \& Electronic Engineering, the University of Hong Kong.

He had been with Shanghai University of Technology, Shanghai, China, from 1991 to 1992 . His research interests include advanced permanent magnet motor drives, electric machine design, numerical analysis of electromagnetic fields in electrical machinery, electric machine controllers, and electric vehicles. He has published several technical papers within these fields.

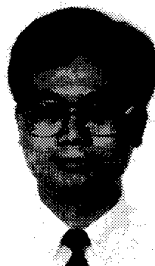

K. T. Chau (M'89) received the first-class honors B.Sc.(Eng.), M.Phil., and Ph.D. degrees all in electrical and electronic engineering from the University of Hong Kong in 1988, 1991, and 1993. respectively.

From 1990 to 1994, he worked as Lecturer in the Department of Electrical Engineering, Hong Kong Polytechnic University. Since 1995, he has been with the Department of Electrical \& Electronic Engineering, the University of Hong Kong. His research interests include advanced motor drives, electric vehicles, and power electronics. He has published over 50 refereed technical papers and several industrial reports.

Dr. Chau was the recipient of the Sir Edward Youde Memorial Fellowships in $1988-89$ and $1989-90$. 